\title{
A single-dose toxicity study on non-radioactive iodinated hypericin for a targeted anticancer therapy in mice
}

\author{
Jun-jie $\mathrm{LI}^{1,2}$, Marlein Miranda CONA ${ }^{1,2}$, Yuan-bo FENG ${ }^{1,2}$, Feng $\mathrm{CHEN}^{1,2}$, Guo-zhi ZHANG ${ }^{1}$, Xue-bin FU ${ }^{1}$, \\ Uwe HIMMELREICH ${ }^{2}$, Raymond OYEN ${ }^{1}$, Alfons VERBRUGGEN ${ }^{3}$, Yi-cheng $\mathrm{NI}^{1,2, *}$ \\ ${ }^{1}$ Theragnostic Laboratory, Department of Imaging and Pathology, Biomedical Sciences Group, KU Leuven, Belgium; ${ }^{2}$ Molecular Small \\ Animal Imaging Centre (MoSAIC), Faculty of medicine, KU Leuven, Belgium; ${ }^{3}$ Faculty of Pharmaceutical Sciences, KU Leuven, Belgium
}

Aim: Hypericin (Hyp) and its radio-derivatives have been investigated in animal models with ischemic heart diseases and malignancies for diagnostic and therapeutic purposes. Before radioiodinated Hyp $\left({ }^{123} \mathrm{I}-\mathrm{Hyp}\right.$ or ${ }^{131} \mathrm{I}$-Hyp) can be considered as a clinically useful drug, vigorous evaluations on its chemotoxicity are necessary. In the present study, we examined the toxicity of a single dose of non-radioactive ${ }^{127}$ I-Hyp in normal mice for $24 \mathrm{~h}$ and $14 \mathrm{~d}$.

Methods: Studies were performed on 132 normal mice. ${ }^{127} \mathrm{I}$-Hyp at a clinically relevant dose of $0.1 \mathrm{mg} / \mathrm{kg}$ body weight and a 100 times higher dose of $10 \mathrm{mg} / \mathrm{kg}$ was intravenously injected into 40 mice. The safety aspects of clinical manifestations, serological biochemistry, and histopathology were assessed. In another 72 mice, ${ }^{127} \mathrm{I}$-Hyp was administered intravenously at assumed values to bracket the value of $\mathrm{LD}_{50}$. The rest 20 mice were used in the control groups.

Results: At $24 \mathrm{~h}$ and $14 \mathrm{~d}$ following the injection of ${ }^{127} \mathrm{I}-\mathrm{Hyp}$ at either $0.1 \mathrm{or} 10 \mathrm{mg} / \mathrm{kg}$, all mice tolerated well without mortality or any observable treatment-related symptoms. No significant differences were found in blood biochemical parameters between the test and control groups. All organs presented normal appearances upon histopathological inspection. The value of $\mathrm{LD}_{50}$ of ${ }^{127} \mathrm{I}-\mathrm{Hyp}$ in mice through intravenous injection was $20.26 \mathrm{mg} / \mathrm{kg}$, with the $95 \%$ confidence interval between $18.90 \mathrm{and} 21.55 \mathrm{mg} / \mathrm{kg}$.

Conclusion: The current study reveals a broad safety range of ${ }^{127} \mathrm{I}-\mathrm{Hyp}$, which not only supports the use of ${ }^{123} \mathrm{I}-\mathrm{Hyp}$ or ${ }^{131} \mathrm{I}-\mathrm{Hyp}$ in the necrosis targeting theragnostic strategy, but also serves as a valuable reference for exploring other possible applications for iodinated Hyp.

Keywords: Hypericin; iodinated compound; single dose toxicity; $\mathrm{LD}_{50}$; targeted anticancer therapy

Acta Pharmacologica Sinica (2012) 33: 1549-1556; doi: 10.1038/aps.2012.111; published online 29 Oct 2012

\section{Introduction}

Hypericum perforatum L, commonly known as St John's Wort ${ }^{[1]}$, has been widely used as an herbal medicine since the time of ancient Greece ${ }^{[2]}$. This plant has attracted interest because of its wound-healing, bactericidal, anti-inflammatory, diuretic and sedative properties ${ }^{[3,4]}$. Hypericin (Hyp), a bioactive ingredient isolated from Hypericum perforatum, possesses the major pharmacological activities found in Hypericum perforatum. In addition to Hypericum perforatum, Hyp has also been found in some fungi and animal species ${ }^{[5]}$. Chemically, Hyp is a red-colored, polycyclic, polyaromatic quinine that structurally belongs to the naphthodianthrones class ${ }^{[5,6]}$. Hyp can either be isolated from the plant or semi-synthetically obtained

\footnotetext{
* To whom correspondence should be addressed.

E-mail yicheng.ni@med.kuleuven.be

Received 2012-03-09 Accepted 2012-07-09
}

from the anthraquinone derivative emodin ${ }^{[7,8]}$.

Hyp exhibits a wide range of pharmacologically interesting properties. Remarkable research and clinical applications include the antidepressant, antiviral, and antitumoral properties of Hyp ${ }^{[5]}$. In addition, Hyp has also been used for cancer photodynamic therapy (PDT) ${ }^{[5,9]}$. The potent photosensitizing property has made Hyp possibly the most powerful naturally occurring photosensitizer described thus far ${ }^{[8]}$. Although numerous pharmacological findings on the potential clinical uses of Hyp have been published, the preclinical efficacy concerning the above utilities still remains controversial ${ }^{[10]}$. During a recent contrast agent study, $\mathrm{Ni}$ et al further expanded the role of Hyp in medicine by revealing that the necrosis avidity of Hyp is superior to its tumor affinity ${ }^{[6,11-13]}$. Therefore, the necrosis avidity of radioiodinated Hyp, such as $\left[{ }^{123} \mathrm{I}\right]$ iodohypericin $\left({ }^{123} \mathrm{I}-\mathrm{Hyp}\right)$, has been used as a diagnostic tool for imaging ischemic myocardial infarction and therapeutic tumor 
necrosis ${ }^{[11-17]}$. Additionally, the potential use of ${ }^{131} \mathrm{I}-\mathrm{Hyp}$ for the treatment of cancer has been investigated with encouraging results, which have been demonstrated in rodent tumor models $^{[13,15]}$.

Although Hyp is very promising and highly researched, phenomena associated with the use of Hyp and its derivatives, such as insolubilization, aggregation, fusion, and relative instability, could hinder the applications of Hyp. The relevance of the chemical and physical properties to the pharmaceutical application of Hyp has been discussed extensively ${ }^{[7,18-28]}$. However, specific clinical applications become more restricted when the focus is narrowed to those newly discovered activities. The toxicological properties of Hypericum perforatum have been tested in different animals for different clinical applications. The toxicity of Hypericum extract LI160, which contains Hyp, and its analog pseudohypericin have been tested orally, both acutely and over a period of 26 weeks in mice, rats, and dogs. The first intolerance reactions appeared at $900 \mathrm{mg} \cdot \mathrm{kg}^{-1} \cdot \mathrm{d}^{-1}$, and the $\mathrm{LD}_{50}$ (half lethal dose) was greater than $5000 \mathrm{mg} / \mathrm{kg}^{[21]}$. Fewer evaluations have been made regarding the toxicity of Hyp and any of its radioiodinated derivatives. Most of the previous studies with Hyp were performed either in vitro or under oral or intraperitoneal administration instead of intravenous (iv) injection, which has provided less valuable information about the novel applications of Hyp. Fox et al demonstrated that the iv application of Hyp was well tolerated by rhesus monkeys at a dose of 2 $\mathrm{mg} / \mathrm{kg}$, but a transient, severe photosensitivity rash occurred at $5 \mathrm{mg} / \mathrm{kg}^{[20]}$. In a phase I study, AIDS patients received Hyp intravenously at $30-40 \mathrm{mg}$ twice weekly. Phototoxic reactions (facial pain and erythema) presented after direct exposure to sunlight within 8 weeks of treatment ${ }^{[22]}$. The $\mathrm{LD}_{50}$ of Hyp was reported to be greater than $23600 \mathrm{mg} / \mathrm{kg}$ in a study that administered Hyp orally in mice ${ }^{[23]}$. Although some data appear to indicate low toxicity for St John's Wort or Hyp, previous preparations containing Hyp were largely unregulated and contained varying amounts of the drug ${ }^{[24]}$. However, data on the toxicity of a single iv dose of Hyp are extremely limited. The $\mathrm{LD}_{50}$ of Hyp via iv injection still remains absent, which is an essential index for characterizing and quantitatively predicting the acute toxicity effects of any chemical. Lack of the $\mathrm{LD}_{50}$ for Hyp might hinder the understanding and clinical progress of Hyp and its derivatives.
With regard to ${ }^{131} \mathrm{I}-\mathrm{Hyp}$, which was used in recent research ${ }^{[15]}$, the radio-toxicities of Iodine-131 have already been well defined in various clinical applications for many decades ${ }^{[25-28]}$. However, the chemotoxicity of ${ }^{131}$ I-Hyp still remains unknown. Therefore, a rigorous evaluation of the toxicity of non-radioactive iodinated Hyp (I-Hyp) would enable and promote the applications of either Hyp or its iodinated derivatives as potentially useful drugs. We conducted the present toxicity study with a single dose of I-Hyp in normal mice for a period of $24 \mathrm{~h}$ and $14 \mathrm{~d}$. We paid special intention to providing the chemotoxicity information of the novel applications of I-Hyp in the recently developed necrosis-targeted anticancer theragnostic strategy and also a valuable reference safety profile for other possible applications.

\section{Materials and methods}

\section{Preparation of non-radioactive iodinated hypericin}

Hyp was purchased from Planta, Austria with a purity $>98.6 \%$ HPLC (minimum 98.6\%) (http://www.planta.at/hyper/ hyper.htm). I-Hyp was synthesized by a standard electrophilic substitution reaction that combined Hyp and sodium iodide-127 in the presence of chloramine- $\mathrm{T}$ in acetonitrile at pH 7.4 for $30 \mathrm{~min}$ (Figure 1). For purification, the compound was precipitated using sodium chloride and removed by centrifugation. The purified I-Hyp was analyzed by reversephase high-performance liquid chromatography (RP-HPLC) and mass spectrometry (MS). The RP-HPLC was equipped with an RP C18 column (Xterra ${ }^{\mathrm{TM}} \mathrm{C} 18,5 \mu \mathrm{m}, 4.6 \mathrm{~mm} \times 150 \mathrm{~mm}$, Waters, Milford MA, USA) and a UV detector (254 nm). A mixture solvent consisting of acetonitrile- $5 \mathrm{mmol} / \mathrm{L} \mathrm{NH}_{4} \mathrm{OAc}$ $(75: 25, v / v)$ at a flow rate of $1 \mathrm{~mL} / \mathrm{min}$ was used as the mobile phase. Mass spectrometry analysis was performed with a time of flight mass spectrometer equipped with an orthogonal ESI probe (Micromass LCT, Manchester, UK) in negative ion mode. Both techniques confirmed the presence of the compound. Then, the compound was re-dissolved in dimethylsulfoxide (DMSO) at a concentration of $8.8 \mathrm{mg} / \mathrm{mL}$.

\section{Animals}

This animal experiment was approved by the institutional ethical committee on animal care and supply. Fifty healthy, normal CD-1 mice (Swiss, 25 male and 25 female) aged 6-8 weeks and weighing between 26-32 $\mathrm{g}$ (female) and 37-43 $\mathrm{g}$ (male) at

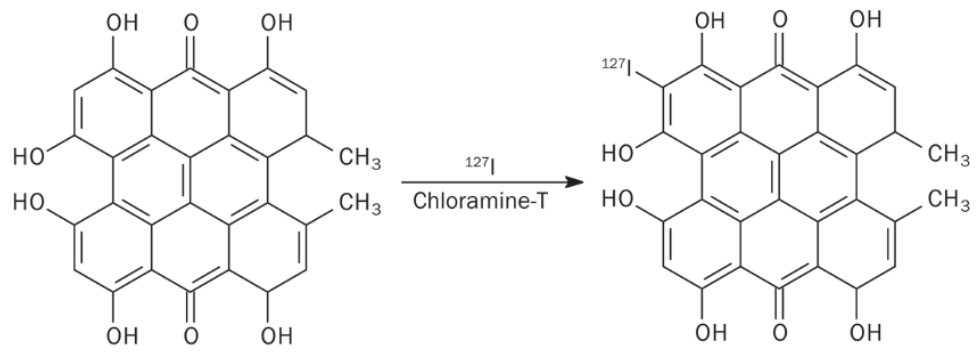

Figure 1. Synthesis of nonradioactive iodinated Hyp $\left({ }^{127} \mathrm{I}-\mathrm{Hyp}\right)$. Being a polyphenolic polycyclic quinone, Hyp can be labeled with iodine-127 in the ortho position of a phenol group. 
the onset of dosing were used for the toxicity study. In addition, normal mice of both genders in equal number weighing approximately $25-30 \mathrm{~g}$ were subjected to $\mathrm{LD}_{50}$ studies $(n=72)$ and to acute toxicity controls of DMSO $(n=10)$. The females were nulliparous and nonpregnant. All mice were housed in polycarbonate cages with wood filing bedding, and food and water were given ad libitum. Each animal was marked on the tail with a different color by permanent marker pens. All mice were acclimatized to the laboratory conditions for $7 \mathrm{~d}$ prior to the initiation of dosing. Environmental conditions were maintained at a temperature of $22 \pm 2{ }^{\circ} \mathrm{C}$ with a relative humidity of $60 \% \pm 10 \%$ and under an equal indoor daily light circle.

\section{Experiments}

As illustrated in Figure 2, mice of the same sex were randomly assigned to the control group $(n=5)$, the 24 h group $(n=10)$ or the $14 \mathrm{~d}$ group $(n=10)$. The latter two groups were further divided into low dose and high dose groups. Mice in the control group received $0.1 \mathrm{~mL}$ of normal saline solution, and the other groups received I-Hyp at either a low or a high dose. The low dose represents the recommended clinical dose ( $0.1 \mathrm{mg} / \mathrm{kg}$ body weight) that has been used in anticancer therapy ${ }^{[14]}$, and the high dose is 100-times greater than the low dose. The mice were anesthetized in an induction chamber with $2 \%$ isoflurane gas in a mixture of $20 \%$ oxygen and $80 \%$ room air at a flow rate of $2 \mathrm{~L} / \mathrm{min}$, and the anesthesia was maintained through a mask during the injection. All iv injections were performed via penile vein (male) or tail vein (female) by an experienced technician. The clinical manifestations, including mortality, change of body weight, general activity level, and food and water intake, were monitored. Blood samples were collected in all mice for standard clinical biochemistry analyses. After blood collection, all mice were euthanized. Internal organs such as the liver, heart, kidney and lungs were excised for gross inspection and histopathological study.

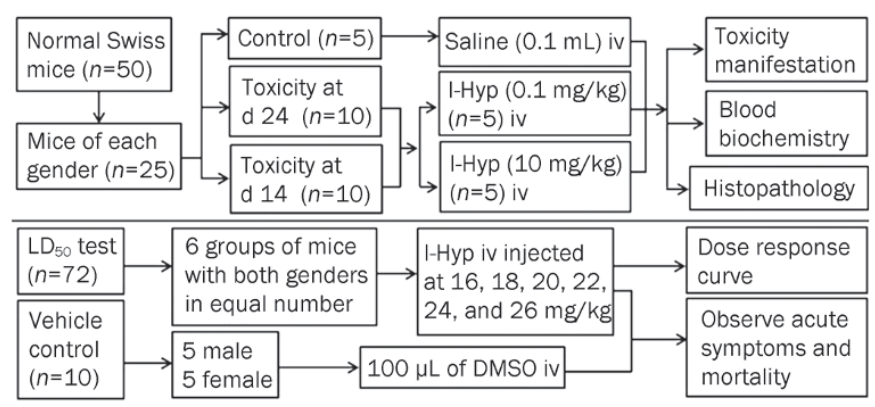

Figure 2. Flow diagram of toxicity experiments with I-Hyp in normal Swiss mice.

\section{Toxicity at $\mathbf{2 4} \mathrm{h}$ post exposure}

Mice were designated to low-dose male, low-dose female, high-dose male and high-dose female groups. I-Hyp was iv administered at 0.1 and $10 \mathrm{mg} / \mathrm{kg}$ body weight in $100 \mu \mathrm{L}$ of
DMSO solution to the low- and high-dose groups, respectively. Observations were recorded systemically for morbidity, eating and drinking, skin changes, general activity level, sensitivity to the light, and respiratory movement. The results were compared with those of the control group.

\section{Toxicity at $14 \mathrm{~d}$ post exposure}

Mice were assigned to groups in the same manner as for studies at $24 \mathrm{~h}$. I-Hyp was given at 0.1 and $10 \mathrm{mg} / \mathrm{kg}$ body weight in $100 \mu \mathrm{L}$ of DMSO solution to the low-dose group and the high-dose group, respectively. The mice were monitored for $14 \mathrm{~d}$ for onset, severity, and reversibility of any toxicity as well as morbidity, general activity level, body weight, sensitivity to the light, skin changes, before being euthanized for clinical biochemistry blood tests and histopathology studies.

\section{Clinical biochemistry blood tests}

Blood samples were collected in non-heparinized tubes and were centrifuged at 3000 rounds per minute $(1837 \times g)$ for 10 min. The serum was separated and analyzed with an IMAGE instrument (Beckman-Coulter) for the following parameters: urea, creatinine, albumin, alkaline phosphatase (ALP), aspartate-aminotransferase (AST), alanine-aminotransferase (ALT), gamma glutamyl transferase (GGT), total bilirubin (TBIL), direct bilirubin (DBIL), creatine kinase (CK), and lactate dehydrogenase (LDH).

\section{Histopathological study}

Histopathological studies of the organs were performed using a previously described method ${ }^{[29]}$. Briefly, the internal organs were fixed in $10 \%$ neutral buffered formalin for $24 \mathrm{~h}$ and dissected into tissue blocks. Samples were dehydrated in ethanol and cleared in benzene to remove the alcohol, and then the samples were infiltrated with molten paraffin at $50^{\circ} \mathrm{C}$ and further embedded into a cubical block of paraffin ${ }^{[24]}$. The paraffinembedded tissues were sectioned into 5 - $\mu \mathrm{m}$ slices by microtome and stained with Hematoxylin and Eosin (H\&E). The slides were examined under an optical microscope (Axioskop; Zeiss, Oberkochen, Germany) with magnifications at $\times 100$ for histopathology, and photomicrographs were obtained using a digital system.

\section{$\mathrm{LD}_{50}$ studies}

Mice that were subjected to $\mathrm{LD}_{50}$ tests were randomly split into 6 groups of 12 mice with an equal number from each gender. Each mouse was anesthetized with isoflurane gas mixed with oxygen by a nose cone. Accordingly, six assumed doses of I-Hyp were iv administered as follows: 16, 18, 20, 22, 24, and $26 \mathrm{mg} / \mathrm{kg}$ in $100 \mu \mathrm{L}$ of DMSO as solvent. The $\mathrm{LD}_{50}$ and $95 \%$ confidence interval for each gender and in combination with both genders were determined from weighted Probit analysis (Bliss and Finney) using SPSS ${ }^{[30,31]}$, and the corresponding dose response curves were generated based on the results. In addition, 10 mice of both genders in equal number $(n=5)$ injected with 100 L of DMSO were used as solvent controls. All mice were observed initially for $2 \mathrm{~h}$ for acute symptoms of toxicity. 
Any mortality observed within $24 \mathrm{~h}$ was registered.

\section{Statistical analysis}

Numerical data were compared between the control group and the studied groups. The values were expressed as the mean \pm standard deviation (SD). Statistical analysis was carried out with the SPSS for Windows software package (version 16.0; SPSS, Chicago, IL, USA). One-way ANOVA was used to elucidate any significant differences between the treatment groups and the control groups. A significant difference was considered for $P$ values less than 0.05 .

\section{Results}

\section{General conditions}

The 50 mice used in the toxicity studies presented normal water and food intake during the study. There were no signs of clinical toxicity, significant changes in body-weight gain, or changes in food consumption. The mice tolerated the iv injection of I-Hyp and solvents without detectable side effects. No mice died of anesthesia. No observable clinical signs such as photophobia, weakness, aggression, restlessness, piloerection, tremors, loss of hair or appetite, diarrhea or ascites appeared in the studied mice.

\section{Toxicity at $24 \mathrm{~h}$ post exposure}

There was no mortality or any treatment-related signs or toxicity observed following the administration of either 0.1 or 10 $\mathrm{mg} / \mathrm{kg}$ body weight of I-Hyp in both male and female mice within $24 \mathrm{~h}$ post injection.

\section{Toxicity at $14 \mathrm{~d}$ post exposure}

All mice survived the duration of the experiments. No alterations in photosensitivity, vivacity, or feces were noted in either the treatment or the control groups during the 2 week study. No changes in the pigmentation of the viscera were observed in any mice. Generally, male mice were heavier than females in both control and treated groups. The median body weight of all mice increased by $3.9 \%-7.6 \%$ during the $14 \mathrm{~d}$ follow up. No significant difference $(P>0.05)$ in the mean body weight was observed between control and treated groups of the same gender.

\section{Clinical biochemistry blood test}

The results of the clinical biochemistry blood test in all studied groups are listed in Table 1. Comparisons were made between control groups and each treated group within the same gender. No significant differences were found in any comparisons.

\section{Histopathology}

Macroscopic and microscopic photomicrographs of the histological sections of the liver, heart, lung, and kidney of the studied mice (collected from mice in the high dose group euthanized on d 14) are presented in Figure 3A, 3B, 3C, 3D, 3A',

Table 1. Effect of I-Hyp on biochemical parameters in mice. Mean \pm SD.

\begin{tabular}{|c|c|c|c|c|c|c|}
\hline \multirow{2}{*}{ Analyst } & \multirow{2}{*}{ Units } & \multirow{2}{*}{ Control } & \multicolumn{2}{|c|}{$24 \mathrm{~h}$} & \multicolumn{2}{|c|}{$14 \mathrm{~d}$} \\
\hline & & & Low dose & High dose & Low dose & High dose \\
\hline \multicolumn{7}{|l|}{ Male } \\
\hline Urea & $\mathrm{mg} / \mathrm{dL}$ & $42.6 \pm 8.0$ & $36.2 \pm 18.0$ & $41.0 \pm 4.0$ & $43.6 \pm 3.9$ & $43.5 \pm 2.1$ \\
\hline Creatinine & $\mathrm{mg} / \mathrm{dL}$ & $0.2 \pm 0.0$ & $0.2 \pm 0.0$ & $0.2 \pm 0.0$ & $0.2 \pm 0.0$ & $0.2 \pm 0.0$ \\
\hline Albumin & $\mathrm{g} / \mathrm{L}$ & $29.1 \pm 3.2$ & $25.4 \pm 8.7$ & $22.0 \pm 7.1$ & $28.7 \pm 1.0$ & $28.9 \pm 1.0$ \\
\hline ALT & $\mathrm{u} / \mathrm{L}$ & $32.4 \pm 8.6$ & $30.2 \pm 21.6$ & $69.0 \pm 39.4$ & $35.5 \pm 7.0$ & $36.0 \pm 6.2$ \\
\hline GGT & $u / L$ & $3.0 \pm 0.0$ & $3.0 \pm 0.0$ & $3.0 \pm 0.0$ & $3.0 \pm 0.0$ & $3.0 \pm 0.0$ \\
\hline TBIL & $\mathrm{mg} / \mathrm{dL}$ & $0.1 \pm 0.0$ & $0.1 \pm 0.0$ & $0.1 \pm 0.0$ & $0.1 \pm 0.0$ & $0.1 \pm 0.0$ \\
\hline DBIL & $\mathrm{mg} / \mathrm{dL}$ & $0.01 \pm 0.0$ & $0.01 \pm 0.0$ & $0.01 \pm 0.0$ & $0.01 \pm 0.0$ & $0.01 \pm 0.0$ \\
\hline $\mathrm{CK}$ & $\mathrm{u} / \mathrm{L}$ & $55.8 \pm 20.6$ & $67.8 \pm 42.9$ & $68.4 \pm 17.3$ & $59.0 \pm 9.2$ & $57.6 \pm 8.6$ \\
\hline Creatinine & $\mathrm{mg} / \mathrm{dL}$ & $0.2 \pm 0.0$ & $0.2 \pm 0.0$ & $0.2 \pm 0.0$ & $0.2 \pm 0.0$ & $0.2 \pm 0.0$ \\
\hline Albumin & $\mathrm{g} / \mathrm{L}$ & $32.5 \pm 2.2$ & $26.8 \pm 6.2$ & $22.6 \pm 9.8$ & $32.1 \pm 1.3$ & $34.1 \pm 2.2$ \\
\hline ALP & $\mathrm{u} / \mathrm{L}$ & $237 \pm 31$ & $200 \pm 127$ & $181 \pm 114$ & $232 \pm 44$ & $228 \pm 42$ \\
\hline AST & $\mathrm{u} / \mathrm{L}$ & $45.6 \pm 4.2$ & $40.2 \pm 23.3$ & $58.0 \pm 18.2$ & $57.8 \pm 21.0$ & $46.6 \pm 22.5$ \\
\hline ALT & $\mathrm{u} / \mathrm{L}$ & $28.4 \pm 8.1$ & $27.6 \pm 17.2$ & $26.4 \pm 3.5$ & $31.4 \pm 1.1$ & $35.2 \pm 9.0$ \\
\hline GGT & $\mathrm{u} / \mathrm{L}$ & $3.0 \pm 0.0$ & $3.0 \pm 0.0$ & $3.2 \pm 0.4$ & $3.0 \pm 0.0$ & $3.0 \pm 0.0$ \\
\hline TBIL & $\mathrm{mg} / \mathrm{dL}$ & $0.1 \pm 0.0$ & $0.1 \pm 0.0$ & $0.1 \pm 0.0$ & $0.1 \pm 0.0$ & $0.1 \pm 0.0$ \\
\hline DBIL & $\mathrm{mg} / \mathrm{dL}$ & $0.01 \pm 0.0$ & $0.01 \pm 0.0$ & $0.01 \pm 0.0$ & $0.01 \pm 0.0$ & $0.01 \pm 0.0$ \\
\hline $\mathrm{CK}$ & $\mathrm{u} / \mathrm{L}$ & $41.8 \pm 8.3$ & $47.2 \pm 25.1$ & $80.2 \pm 60.4$ & $51.2 \pm 17.9$ & $54.4 \pm 14.2$ \\
\hline LDH & $\mathrm{u} / \mathrm{L}$ & $341 \pm 101$ & $189 \pm 136$ & $307 \pm 175$ & $255 \pm 69$ & $346 \pm 99$ \\
\hline
\end{tabular}


A
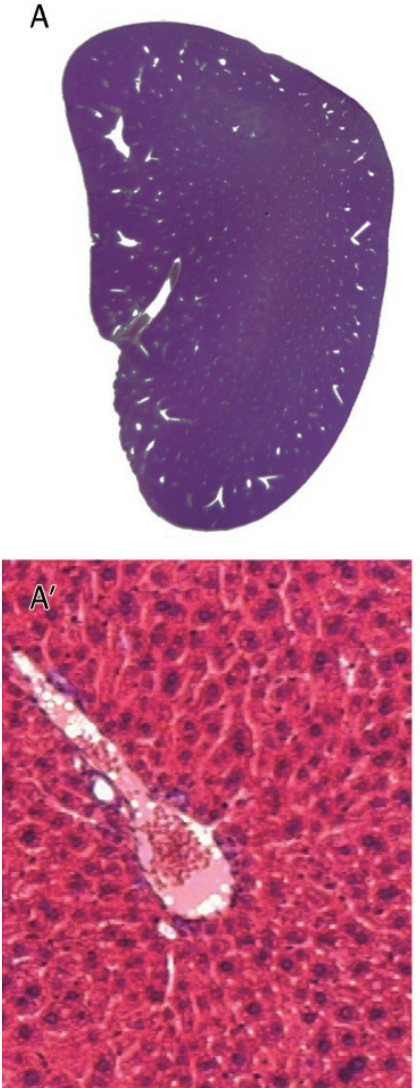

B
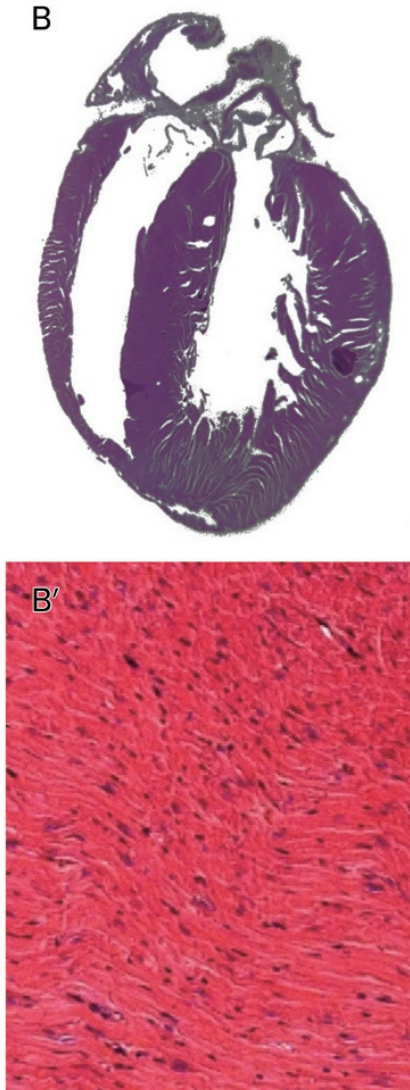

C
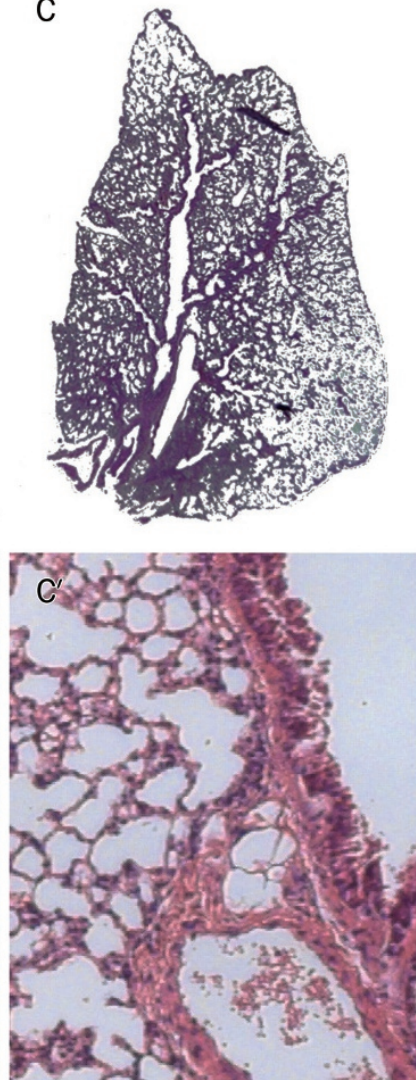

D
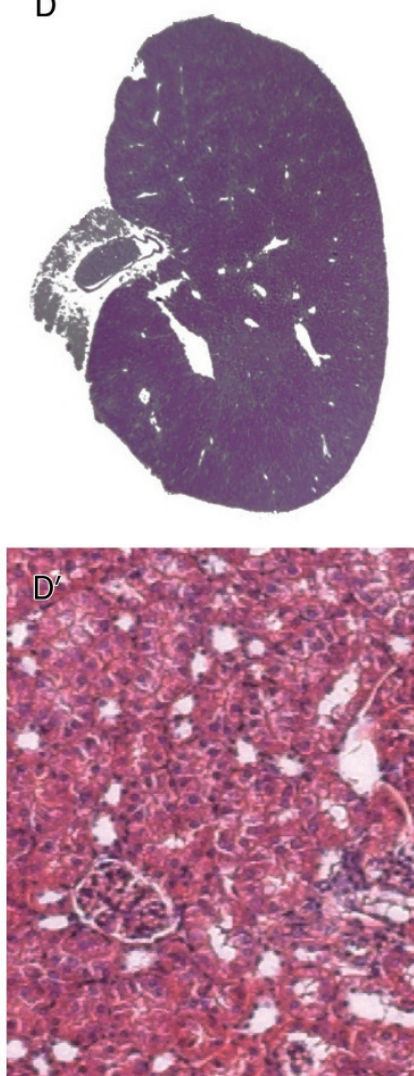

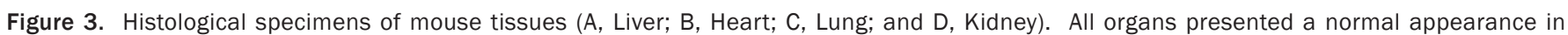

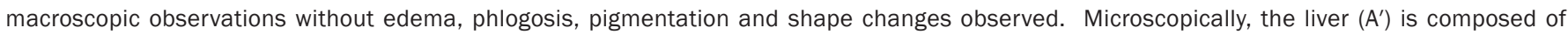

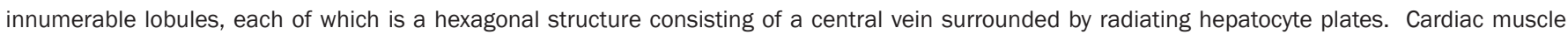

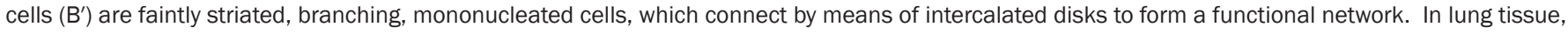

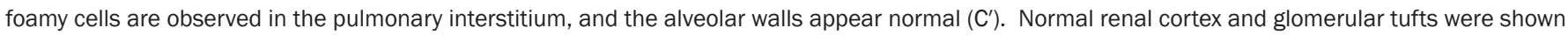
in kidney sections $\left(D^{\prime}\right)$.

$3 \mathrm{~B}^{\prime}, 3 \mathrm{C}^{\prime}, 3 \mathrm{D}^{\prime}$. All of the organs presented a normal appearance in both macroscopic and microscopic observations. No morphological or structural changes, including edema, necrosis, inflammation, or pigmentation, were observed within all organs in the histopathology study.

\section{$\mathrm{LD}_{50}$ studies}

The results of the $\mathrm{LD}_{50}$ studies are listed in Table 2, and the corresponding dose response curve is shown in Figure 4. A transient or permanent respiratory depression was observed in mice at doses of $16 \mathrm{mg} / \mathrm{kg}$ and above. Most animals presented restlessness, aconuresis, clonicity hyperspasmia, opisthotonos, and dyspnea before death. The $\mathrm{LD}_{50}$ values of I-Hyp via iv injection in males, females, and in both genders in combination were found to be $21.23,19.30$, and $20.26 \mathrm{mg} / \mathrm{kg}$, with the $95 \%$ confidence intervals of 19.35-23.21, 16.73-21.20, and $18.90-21.55 \mathrm{mg} / \mathrm{kg}$, respectively.

\section{Discussion}

Hyp and its radio-derivatives have been investigated in animal models with ischemic heart diseases and malignancies for

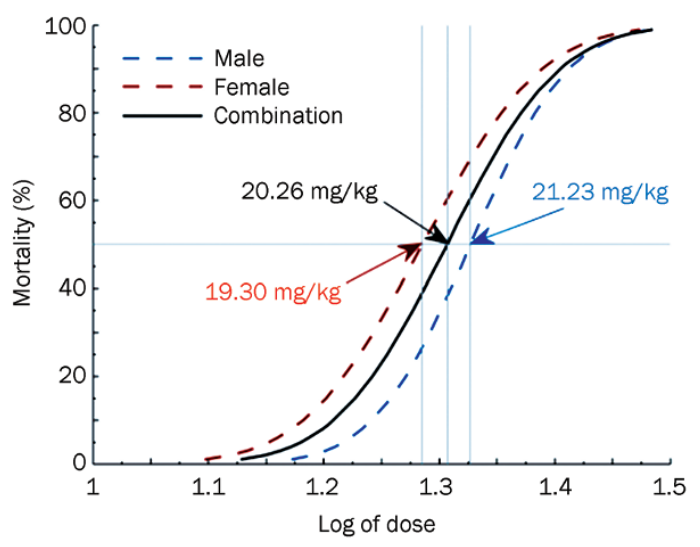

Figure 4. Dose-response curves and the $L_{50}$ were generated based on the results of Probit analysis for males, females and for both genders in combination.

diagnostic and therapeutic purposes ${ }^{[11,14,15,18,32]}$. Toxicity information is an indispensable part for exploring and integrating the targeting anticancer theragnostic strategy using radioiodi- 
Table 2. Acute $\mathrm{LD}_{50}$ tests of I-Hypericin of normal Swiss mice in male, female and both genders in combination, with DMSO as the solvent control. Groups of mice were iv injected with different doses of non-radioactively iodinated Hypericin (I-Hyp). In the vehicle control, $100 \mu \mathrm{L}$ of DMSO injected into 10 mice did not reveal any observable side effects or animal death.

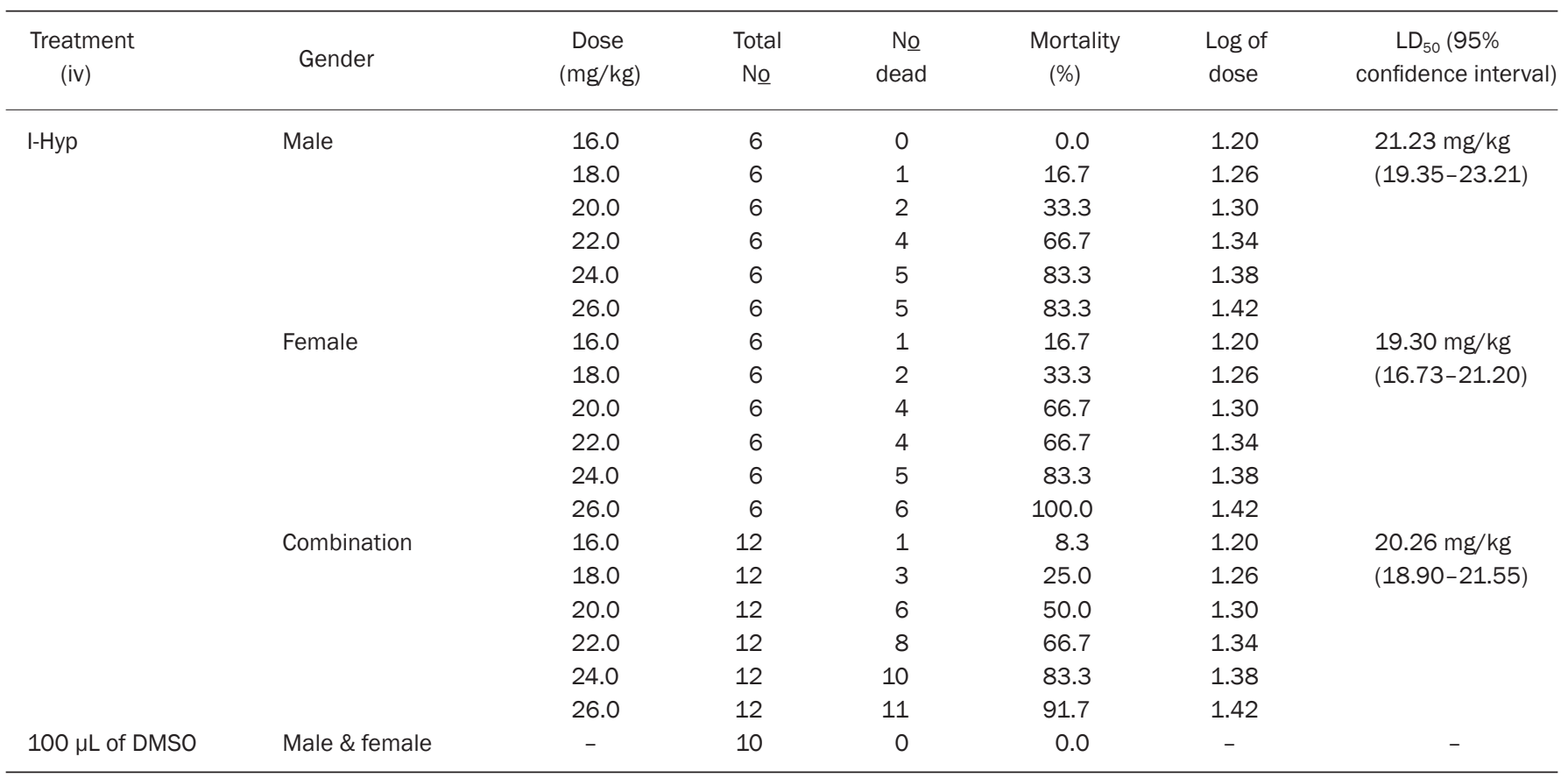

Animals were observed initially for $2 \mathrm{~h}$ for acute symptoms of toxicity. Any mortality observed within $24 \mathrm{~h}$ was registered for analysis.

nated $\mathrm{Hyp}^{[13,15]}$. We report in this study the toxic effects and the $\mathrm{LD}_{50}$ of I-Hyp via iv injection.

In a recent preliminary study, ${ }^{131}$ I-Hyp was used at a radioactive dose of $300 \mathrm{MBq} / \mathrm{kg}$ to target necrotic malignancies for clearing residual viable tumor cells ${ }^{[15]}$. The amount of Hyp used to form the equivalent radioactive dose was approximately $0.1-0.2 \mathrm{mg} / \mathrm{kg}$ of body weight. Thus, the studied doses of $0.1 \mathrm{mg} / \mathrm{kg}$ and $10 \mathrm{mg} / \mathrm{kg}$ body weight cover all of the possible ranges for its new applications.

Hyp is generally well tolerated, and the side effects mainly include photosensitivity, photodermatitis, constipation, mood or mental changes, dizziness or fatigue, muscle tremors, decreased sexual libido ${ }^{[33]}$. A previous study revealed that Hyp is well tolerated at a systemic dose of $40 \mathrm{mg} / \mathrm{kg}$ in mice $^{[34]}$, while severe dose-limiting photosensitivity presenting as a skin rash was reported in another study with iv injection of Hyp at a single dose of $5 \mathrm{mg} / \mathrm{kg}$ in rhesus monkeys ${ }^{[20]}$. This discrepancy might be due to the following: 1) there is a higher photo-tolerance in mice than in rhesus monkeys; or 2) Hyp is more tolerable when injected intraperitoneally than intravenously. In the present study, none of the mice showed obvious toxic manifestations after a single dose of I-Hyp at 0.1 $\mathrm{mg} / \mathrm{kg}$ and $10 \mathrm{mg} / \mathrm{kg}$ body weight, which might have been caused by the photochemical property change after the substitution of iodine onto the intact Hyp structure to form I-Hyp. Severe toxicity and a loss of appetite may be accompanied by a loss of body weight, but the mice in the 14-d studies gained weight at the same rate as the control groups during the 2 weeks of follow-up, which reflects no toxicity or less toxicity at the studied doses.

The results of the blood biochemical tests with obvious deviations from the normal control were chosen for discussion. A low level of serum albumin normally indicates diseases such as liver dysfunction, nephritic syndrome, genetic variations, and malignancies. However, decreased albumin levels are not observed in acute liver failure until several weeks before the impaired albumin production drops the serum albumin level ${ }^{[35]}$. In this study, the slightly decreased serum albumin in some cases of the acute phase high dose group cannot represent substantial organ damage but might indicate a temporary depletion of serum albumin due to protein binding of I-Hyp for blood-borne transportation and body distribution after iv administration. ALT and AST are two liver enzymes that are associated with hepatocellular injury. ALT is a cytosolic enzyme specific for liver, and AST is also present in the myocardium, skeletal muscle, brain, and kidneys. The serum levels of ALT and AST were both slightly elevated in the male high-dose group of the $24 \mathrm{~h}$ study, which may be caused by a transient hepatotoxicity of liver cells. As recommended by the 2002 American Gastroenterological Association guidelines for any hepatotoxic drug, only a single ALT and AST elevation of three times the upper limit of the normal range was considered as a reason for discontinuation of treatment ${ }^{[36]}$. The slight increase of ALT and AST levels does not impose an argument for ending treatment with I-Hyp. The slight increase of blood urea in the female groups at the dose of $10 \mathrm{mg} / \mathrm{kg}$ of body 
weight may suggest a subtle disturbance of kidney function. Further evidence is needed to address the renal toxicity at higher doses. However, renal toxicity should not be present at a clinically relevant dose. There were no obvious changes observed in other parameters such as GGT, TBIL, and DBIL, CK, and LDH. Gross examination of internal organs and histopathological studies from all of the mice revealed no detectable cell death or abnormalities.

The studies of single dose I-Hyp helped to not only verify any toxicity at the acute phase of $24 \mathrm{~h}$ but also to evaluate the morphological and physiological changes of organs and the tendency of body weight to change at the sub-acute phase of $14 \mathrm{~d}$. I-Hyp at either a clinically relevant dose or 100-times the clinical dose was proven to be either low or non-toxic in the studies. The $\mathrm{LD}_{1}$ value of I-Hyp was more than 130 times that of the recommended therapeutic dose that was used in targeting cancer therapy, which suggests a negligible chemotoxicity of I-Hyp and a wide safety range for its clinical use.

Despite the long history of its medicinal applications, few toxicological studies with purified Hyp have been conducted. For the first time to our knowledge, we performed toxicity studies for I-Hyp, and the results present strong evidence of acceptable safety and low toxicity at a single dose range from 0.1 to $10 \mathrm{mg} / \mathrm{kg}$ body weight within $24 \mathrm{~h}$ and $14 \mathrm{~d}$ post exposure in mice of both genders. The current study with I-Hyp not only provides supportive toxicity information for its use in necrosis-targeting anticancer theranostic strategy ${ }^{[15,37]}$ but might also set a valuable reference for other utilities of Hyp and its radioiodinated derivatives.

\section{Acknowledgements}

This work was partially supported by the grants awarded by FWO Vlaanderen ZWAP/05/018; Geconcerteerde Onderzoeksactie of the Flemish Government, OT project (OT/06/70); the KU Leuven Molecular Small Animal Imaging Center MoSAIC (KUL EF/05/08); the center of excellence In vivo Molecular Imaging Research (IMIR) of KU Leuven; the IWT SBO 'Imagine' (SBO80017) and an EU project Asia-Link CfP 2006EuropeAid/123738/C/ACT/Multi-Proposal № 128-498/111. The corresponding author, Yi-cheng NI, is currently a Bayer Lecture Chair holder.

\section{Author contribution}

Study concept and design: Jun-jie LI, Marlein Miranda CONA and Yi-cheng NI; experimental performance: Jun-jie LI, Marlein Miranda CONA, Yuan-bo FENG, Feng CHEN, Guo-zhi ZHANG, Xue-bin FU, and Yi-cheng NI; literature search and manuscript drafting or editing: Jun-jie LI, Marlein Miranda CONA, Yuan-bo FENG, Feng CHEN, and Yi-cheng NI; manuscript revision for intellectual content: Jun-jie LI, Marlein Miranda CONA, Yuan-bo FENG, Feng CHEN, Guozhi ZHANG, Xue-bin FU, Uwe HIMMELREICH, Raymond OYEN, Alfons VERBRUGGEN, and Yi-cheng NI; approval of final version of submitted manuscript: Jun-jie LI, Marlein Miranda CONA, Yuan-bo FENG, Feng CHEN, Guozhi ZHANG, Xue-bin FU, Uwe HIMMELREICH, Raymond
OYEN, Alfons VERBRUGGEN, and Yi-cheng NI.

\section{References}

1 Hölzl J, Ostrowski E. Analysis of the Essential Compounds of Hypericum perforatum. Planta Med 1986; (6): 531.

2 Tammaro F, Xepapadakis G. Plants used in phytotherapy, cosmetics and dyeing in the Pramanda district (Epirus, North-West Greece). J Ethnopharmacol 1986; 16: 167-74.

3 Crak C, Radusiene J, Janulis V, Ivanauskas L. Secondary metabolites in Hypericum perfoliatum: variation among plant parts and phenological stages. Bot Helv 2007; 117: 29-36.

4 Diasa ACP, Seabrab RM, Andradeb PB, Ferreresc F, FernandesFerreiraa M. Xanthone biosynthesis and accumulation in calli and suspended cells of Hypericum androsaemum. Plant Sci 2000; 150: 93-101.

5 Karioti A, Bilia AR. Hypericins as potential leads for new therapeutics. Int J Mol Sci 2010; 11: 562-94.

6 Marysael T, Ni Y, Lerut E, de Witte P. Influence of the vascular damaging agents DMXAA and ZD6126 on hypericin distribution and accumulation in RIF-1 tumors. J Cancer Res Clin Oncol 2011; 137: 1619-27.

7 Kubin A, Wierrani F, Burner U, Alth G, Grünberger W. Hypericin - the facts about a controversial agent. Curr Pharm Des 2005; 11: 23353.

8 Agostinis P, Vantieghem A, Merlevede W, de Witte PA. Hypericin in cancer treatment: more light on the way. Int J Biochem Cell Biol 2002; 34: 221-41.

9 Head CS, Luu Q, Sercarz J, Saxton R. Photodynamic therapy and tumor imaging of hypericin-treated squamous cell carcinoma. World J Surg Oncol 2006; 4: 87.

10 Kubin A, Wierrani F, Burner U, Alth G, Grünberger W. Hypericin - the facts about a controversial agent. Curr Pharm Des 2005; 11: 23353.

11 Ni Y, Huyghe D, Verbeke K, de Witte PA, Nuyts J, Mortelmans L, et al. First preclinical evaluation of mono-[ $\left.{ }^{123} \mathrm{I}\right]$ iodohypericin as a necrosisavid tracer agent. Eur J Nucl Med Mol Imaging 2006; 33: 595-601.

12 Ni Y, Bormans G, Chen F, Verbruggen A, Marchal G. Necrosis avid contrast agents: functional similarity versus structural diversity. Invest Radiol 2005; 40: 526-35.

13 Li J, Chen F, Cona MM, Feng Y, Himmelreich U, Oyen R, et al. A review on various targeted anticancer therapies. Target Oncol 2012; 7: 69-85.

14 Fonge $\mathrm{H}$, Vunckx $\mathrm{K}$, Wang $\mathrm{H}$, Feng $\mathrm{Y}$, Mortelmans L, Nuyts J, et al. Non-invasive detection and quantification of acute myocardial infarction in rabbits using mono-[ ${ }^{123}$ I]iodohypericin microSPECT. Eur Heart J 2008; 29: 260-9.

15 Li J, Sun Z, Zhang J, Shao H, Cona MM, Wang H, et al. A dual-targeting anticancer approach: soil and seed principle. Radiology 2011; 260: 799-807.

16 Van de Putte M, Wang $\mathrm{H}$, Chen $\mathrm{F}$, de Witte PA, Ni Y. Hypericin as a marker for determination of tissue viability after intratumoral ethanol injection in a murine liver tumor model. Acad Radiol 2008; 15: 107 13.

17 Van de Putte M, Wang H, Chen F, De Witte PA, Ni Y. Hypericin as a marker for determination of tissue viability after radiofrequency ablation in a murine liver tumor model. Oncol Rep 2008; 19: 927 32.

18 Marysael T, Bauwens M, Ni Y, Bormans G, Rozenski J, de Witte P. Pretargeting of necrotic tumors with biotinylated hypericin using ${ }^{123}$ Ilabeled avidin: evaluation of a two-step strategy. Invest New Drugs 
2011. doi: $10.1007 / \mathrm{s} 10637-011-9778-2$.

19 Van de Putte M, Ni Y, De Witte PA. Exploration of the mechanism underlying the tumor necrosis avidity of hypericin. Oncol Rep 2008; 19: 921-6.

20 Fox E, Murphy RF, McCully CL, Adamson PC. Plasma pharmacokinetics and cerebrospinal fluid penetration of hypericin in nonhuman primates. Cancer Chemother Pharmacol 2001; 47: 41-4.

21 Leuschner J. Gutachten zur experimentellen Toxikologie von Hypericum-Extract LI 160. Berlin: Lichtwer Pharma GmbH. 1995.

22 Gulick RM, McAuliffe V, Holden-Wiltse J, Crumpacker C, Liebes L, Stein DS, et al. Phase I studies of hypericin, the active compound in St. John's wort, as an antiretroviral agent in HIV-infected adults. AIDS Clinical Trials Group Protocols 150 and 258. Ann Intern Med 1999; 130: 510-4.

23 Cui Y, Liang J, Luo Y, Wang X, Zhu Y, Shang R, et al. Acute toxicity tests of extractum hypericin. Chin J Vet Drug 2005; 39: 19-20.

24 Stowell RE. Effect on tissue volume of various methods of fixation, dehydration, and embedding. Biotechnic \& Histochemistry 1941; 16: 67-83.

25 Watanabe N, Yokoyama K, Kinuya S, Shuke N, Shimizu M, Futatsuya R, et al. Radiotoxicity after iodine-131 therapy for thyroid cancer using the micronucleus assay. J Nucl Med 1998; 39: 436-40.

26 Narra VR, Howell RW, Harapanhalli RS, Sastry KS, Rao DV. Radiotoxicity of some iodine-123, iodine-125 and iodine-131-labeled compounds in mouse testes: implications for radiopharmaceutical design. J Nucl Med 1992; 33: 2196-201.

27 Shapiro B, Sisson JC, Wieland DM, Mangner TJ, Zempel SM, Mudgett E, et al. Radiopharmaceutical therapy of malignant pheochromocytoma with [ ${ }^{131}$ I]metaiodobenzylguanidine: results from ten years of experience. J Nucl Biol Med 1991; 35: 269-76.

28 Order SE, Stillwagon GB, Klein JL, Leichner PK, Siegelman SS, Fishman EK, et al. Iodine-131 antiferrin, a new treatment modalityin hepatoma a Radiation Therapy Oncology Group study. J Clin Oncol 1985; 3: 1573-82.

29 Vincek V, Nassiri M, Nadji M, Morales AR. A tissue fixative that protects macromolecules (DNA, RNA, and protein) and histomorphology in clinical samples. Lab Invest 2003; 83: 1427-35.

30 Finney DJ, Ed. Probit Analysis. Cambridge, England, Cambridge University Press 1952.

31 Finney DJ, Stevens WL. A table for the calculation of working probits and weights in probit analysis. Biometrika 1948; 35: 191-201.

32 Song S, Xiong C, Zhou M, Lu W, Huang Q, Ku G, et al. Small-animal PET of tumor damage induced by photothermal ablation with ${ }^{64} \mathrm{Cu}$-bisDOTA-hypericin. J Nucl Med 2011; 52: 792-9.

33 http://www.livestrong.com/article/107004-hypericin-side-effects/

34 Luksiene Z, de Witte PA. Hypericin as novel and promising photodynamic therapy tool: studies on intracellular accumulation capacity and growth inhibition efficiency. Medicina (Kaunas) 2003; 39: 67782.

35 Nagao Y, Sata M. Serum albumin and mortality risk in a hyperendemic area of HCV infection in Japan. Virol J 2010; 7: 375.

36 Onusko E. Statins and elevated liver tests: what's the fuss? J Fam Pract 2008; 57: 449-52.

37 Li J, Cona MM, Chen F, Feng Y, Zhou L, Yu J, et al. Exploring theranostic potentials of radioiodinated hypericin in rodent necrosis models. Theranostics 2012; 2: 1010-9. 